\title{
Fuzzy Sets and Game Theory in Green Supply Chain: An Optimization Model
}

\author{
Marwan Alakhras ${ }^{1(\bowtie)}$, Mousa Hussein ${ }^{1}$, and Mourad Oussalah ${ }^{2}$ \\ ${ }^{1}$ EE, COE, United Arab Emirates University, Al Ain, United Arab Emirates \\ \{alakhras,mihussein\}@uaeu.ac.ae \\ ${ }^{2}$ Department of Computer Science and Engineering, \\ University of Oulu, Oulu, Finland \\ Mourad.Oussalah@oulu.fi
}

\begin{abstract}
An optimization model using fuzzy sets and game theory for three players is put forward in this wok. The decision model is influenced by customer demands in a green supply chain. The proposed model includes an empirical solution to enhance the confidence level of players to choose plausible green strategy. Initially, the strategies are formulated using the game theory as manufacturer, costumer and government, to be able to optimize the pay-off uncertainty conditions of demands, by combining computational fuzzy set with ability of sensitive analysis of related fuzzy parameters to enhance the calculations and problem solving, with presenting Nash equilibrium the problem solving part.
\end{abstract}

Keywords: Fuzzy sets $\cdot$ Game theory $\cdot$ Nash equilibrium • Green supply chain · Pay off function · Green strategy

\section{Introduction}

Due to the astonishing growth of green supply chain approaches, and sustainable development, this subject attracted many researchers. Traditionally, most of methods and models often were presented to conceptually justify green supply chain. However, the issue here is to be able to exactly find and plausible solutions, that motivate the main players in any supply chain to pick an accurate solution under uncertainty conditions. Any valid solution should definitely constitute of various mathematical models, which are sensitive to changes in the trading industries.

In our work, we considered merging of game theory and fuzzy sets to analyze and model green supply chain strategies, to make a more plausible fuzzy game model with deployment of players, decision-making parameters of pay-off functions. In which, major parameters, and players' pay-off functions are optimized in order to accurately analyze results for players, and achieve enhanced confidence in choosing a certain strategy. This model aims at the government and manufacturers abilities to analyze the customer inquiries, what strategy they usually pick considering the income and cost tradeoff to change status. Where an optimization model is put forward to choose the best cost/income parameters of players pay-off (pricing, subsidiaries...), based on customer demand. Due to the vagueness in the real world data, then a fuzzy inference system that depends on game theory looks promising, especially, in green supply chain, 
this can build a better practical solution in order to optimize related functions and variables. And for more comprehensive analysis, a game model of three-players, namely (government, manufacturer and customer) has been considered. Hence, the final results of this work show that if the green strategies are considered by players, the game fuzzy model can provide more economic results in players' pay-off than the nonfuzzy game model.

The remaining part of this work is organized as follows: Sect. 2 lists some of the work done in the literature. In Sect. 3, the modelling of the problem is elaborated. Section 4 describes modelling of the problem with applying Fuzzy Set theory concepts with sensitive analysis. Section 5 details the simulation and application considered for the proposed fuzzy model with optimal solution. In Sect. 6, Numerical analysis with case study is provided. And finally, the conclusion is drawn.

\section{Literature Review}

Since the early 1980's the topics of supply chain management attracted many researchers [1-4], particularly to look at this problem from programming point of view. Where, concepts like material selection, production process, transportation, and definitely the interaction between various supply chain constitutes have always been investigated. Recently, due to reduction of resources, increase in environmental pollutions because of trade developments, and the growth of customers inquiries, green supply chain also affected by these changes, where, the challenge was to enhance environmental effects and increase economic revenue [5]. The definition of Green supply chain management was also considered in [6]. On one hand, it was claimed that; the enhancement of long-term economic revenue, in addition to enhancement of environmental impacts can be considered as win-win strategy [7, 8].

On another hand, Green supply chain management does not have solely impact on environment, but also it has a direct impact on manufacturers. One may consider the green product progress, increase in opportunities and re-innovation of products [9]. Moreover, using developed technologies in supply chain management and processes to decrease industrial pollution is another issue to consideration the impact on environment was discussed in [10]. For example, the some researchers [11] considered the carbon emission life cycle model as important tool help users in picking certain products, and likewise, can be considered as tool for manufacturers while Game theory can be considered as an important technique, especially, when conflicts of interest among players are rising. Essentially to assist decision makers to increase positive collaboration to satisfy common goals [12]. Practical game theory is often considered parallel in both streams the supply chain from one side and economic stability from the other side as in [13-16]. Also evolutional game models have been considered to establish rationale relations between various subsidies and governmental penalties, definitely this would affect environmental performance of companies [17]. In this particular work in 2007, the authors suggested imposing environmental performance and regulations by governments to have direct impact on subsidies through set of penalties. Later on in 2009 and 2011 other versions of game theory were proposed to assist in putting clear pricing policies on regulations on the environment performance 
$[18,19]$. Particularly, a symmetric bargaining model of the game theory was suggested. Another model in 2012 [20] was proposed based on dynamic evolutionary game theory. The proposed model studied potential coordination among various players, namely, retailers and manufacturers, through optimizing long term economic benefits, and environment impact, based on win-win green supply conditions. One particular case was considered in [21]. This case considered the relationship between optimizing the Carbon emission and economic benefits.

Those studies, essentially presented the use of game theory in supply chain, worth to mention that many of them presented the two-players model case, with simple techniques for the presented conditions. In our work, three players on the chain were simultaneously considered, costumer, manufacturer and government. This combination differentiates our work from the previous studies. Moreover, this distinction allows us to study the effectiveness of various parameters in the players pay-off function. In addition, the use of fuzzy set theory and fuzzy inference system allows us to generate more plausible model, especially with the use of sensitivity analysis which achieves optimal results under uncertainty conditions.

\section{Modelling Principle}

In order to be able to clarify the modelling of the problem, initially the description of main parameters have to be set to the common ground, this includes the main income and cost parameters for the Subsidiaries considered in this particular problem i.e., Government, Manufacturer, and Customer. For the income purposes, income acquired from some financial facilities, i.e., credits, loans...etc., can be considered as sources for income for the governments. Whereas, Tax reduction, Custom charges reduction, Loans, and any other special facilities can be considered as income for manufacturers. While, after sale services, special payment condition, discounts, etc. are considered as incomes for customers. The long term income variable like sustainable development benefits which has direct impact on players' decision-making especially for manufacturers and government.

Costs variable can vary, for instance: Environmental costs may include costs of miss-using of resources, environmental pollution, and the resultant human risks to human. Unemployment Cost variable, which is usually studied by governments due to change of technology used by certain manufacturer. Subsidiary cost variable, this can be the cost that a player considers as subside or decline of other members of the game. The variable cost of manufacturing technology, which can include training costs, maintaining costs, energy costs, etc. will be added as direct costs for the manufacturing. Losing credit costs, loss international or government credit in the event of nonimplementation of international green industry related requirements has to be an added cost. 
Now let $N$ be the set of participating players and $S$ the set of considered strategies that can be defined as:

$$
S_{i}=\left\{S_{1}, S_{2}, \ldots, S_{k}\right\} i \in N=\{1,2,3\}
$$

The variables of decision making strategies are described in the Table 1 .

Table 1. Players considered strategies

\begin{tabular}{l|l|l}
\hline Government (1) & Customers (2) & Manufacturer (3) \\
\hline Passive & Inquiries increase & Maintain standard \\
\hline Monitor & Passive & Update to tolerable standard \\
\hline Sub system & Inquiries increase & Update to acceptable standard \\
\hline
\end{tabular}

Based on the above variables and relationships, then pay-off function can be modeled as follows:

$$
\begin{gathered}
\forall S_{x y}, P_{x y}=\sum_{a=1}^{k}\left(I_{x a}\right)_{S_{x y}}-\sum_{b=1}^{l}\left(C_{x b}\right)_{S_{x y}} \\
x, y=1,2,3 \\
a=1,2, \ldots, k \\
b=1,2, \ldots, l
\end{gathered}
$$

Where, $S_{x y}$ is the strategy $(x)$ that is chosen by player $(y), P_{x y}$ is pay-off of player (y) if strategy $(x)$ is selected, $\left(I_{x a}\right)_{S_{x y}}$ is the income $(a)$ of player $(y)$ if strategy $(x)$ is selected, $\left(C_{x b}\right)_{S_{x y}}$ is cost $(b)$ of player $(y)$ if strategy $(x)$ is selected, $y$ is the number of players (1: government, 2: Customer, 3: Manufacturer), $x$ is the number of strategies, $a$ is the number of income, and $b$ is the number of cost. Where details of income and cost variables for each player are described in Tables 2 and 3:

Table 2. The income variables of pay-off

\begin{tabular}{l|l|l}
\hline Government (1) & Customers (2) & Manufacturer (3) \\
\hline Penalties & Subsidiary & Sale \\
\hline Int. Subsidiary & $\begin{array}{l}\text { Sustainable development } \\
\text { benefit }\end{array}$ & Subsidiary \\
\hline $\begin{array}{l}\text { Sustainable development } \\
\text { benefit }\end{array}$ & $\begin{array}{l}\text { Sustainable development } \\
\text { benefit }\end{array}$ \\
\hline
\end{tabular}


Table 3. The cost variables of pay-off

\begin{tabular}{l|l|l}
\hline Government (1) & Customers (2) & Manufacturer (3) \\
\hline Monitor & Purchasing & Investment \\
\hline Subsidiary & Environment & Production \\
\hline Environment & & Subsidiary \\
\hline Losing credit & & Overhead \\
\hline Unemployment & & Penalties \\
\hline
\end{tabular}

If the parameters; $\alpha$ and $\gamma$ defined as, the penalty rate of manufacturer in relation to income due to selling of products, the parameter $\beta$ is the rate of increase in price of products in case of technology change, $\gamma$ is the manufacturer's percent of share from incentive budget of government, and $\varepsilon$ is the customers' cost if increase of demand is seen in state of no change of technology. Then according to Eq. (2), Tables 2 and 3, the players pay-off functions could be formulated as:

$$
P_{1}=\left(I_{11}+I_{12}+I_{13}\right)-\left(C_{11}+C_{12}+C_{13}+C_{14}+C_{15}\right)
$$

Where, $I_{11}=\alpha(1+\beta)(1+\rho) I_{21}$, and $C_{12}=\gamma C_{12}+(1-\gamma) C_{12}$

$$
\text { then: } P_{1}=\left[\alpha(1+\beta)(1+\rho) I_{21}+I_{12}+I_{13}\right]-\left[\left(C_{11}+\gamma C_{12}+(1-\gamma) C_{12}+C_{13}+C_{14}+C_{15}\right)\right]
$$

$$
P_{2}=\left[\alpha(1+\beta)(1+\rho) I_{21}+I_{22}+I_{23}\right]-\left(C_{21}+\varphi(1+\rho) C_{22}+C_{23}+C_{24}+C_{25}\right)
$$

Where $I_{22}=\gamma C_{12}$, and $C_{25}=\alpha(1+\beta)(1+\rho) I_{21}$

$$
\begin{aligned}
P_{2}= & {\left[(1+\beta)(1+\rho) I_{21}+\gamma C_{12}+I_{23}\right] } \\
& -\left(C_{21}+\varphi(1+\rho) C_{22}+C_{23}+C_{24}+\alpha(1+\beta)(1+\rho) I_{21}\right)
\end{aligned}
$$

then: $P_{2}=\left[(1-\alpha)(1+\beta)(1+\rho) I_{21}+\gamma C_{12}+I_{23}\right]-\left(C_{21}+\varphi(1+\rho) C_{22}+C_{23}+C_{24}\right)$

$P_{3}=\left(I_{31}+I_{32}\right)-\left(C_{31}+C_{32}\right)$, where $I_{31}=(1-\gamma) C_{12}$, and $C_{31}=(1+\beta) I_{21}+$ $\beta \rho I_{21}+\varepsilon=(1+\beta+\beta \rho) I_{21}+\varepsilon$

$$
\text { then: } P_{3}=\left[(1-\gamma) C_{12}+I_{32}\right]-\left[(1+\beta+\beta \rho) I_{21}+\varepsilon+C_{32}\right]
$$

Then the three player's matrix can be described as shown in Tables 4, 5, and 6 . 
Table 4. Matrix model for Customer's strategy $=S_{31}$

\begin{tabular}{|c|c|c|c|}
\hline & $\begin{array}{l}\text { Manufacturer } \\
\text { strategy }=S_{21}\end{array}$ & $\begin{array}{l}\text { Manufacturer } \\
\text { strategy }=\boldsymbol{S}_{22}\end{array}$ & $\begin{array}{l}\text { Manufacturer } \\
\text { strategy }=S_{23}\end{array}$ \\
\hline $\begin{array}{l}\text { Government } \\
\text { strategy }=S_{11}\end{array}$ & $\begin{array}{l}\sum_{i=1}^{3}\left(I_{1 i}\right)_{S_{11}}-\sum_{j=1}^{5}\left(C_{1 j}\right)_{S_{11}} \\
\sum_{i=1}^{3}\left(I_{2 i}\right)_{S_{21}}-\sum_{j=1}^{5}\left(C_{2 j}\right)_{S_{21}} \\
\sum_{i=1}^{2}\left(I_{3 i}\right)_{S_{31}}-\sum_{j=1}^{2}\left(C_{3 j}\right)_{S_{31}}\end{array}$ & $\begin{array}{l}\sum_{i=1}^{3}\left(I_{1 i}\right)_{S_{11}}-\sum_{j=1}^{5}\left(C_{1 j}\right)_{S_{11}} \\
\sum_{i=1}^{3}\left(I_{2 i}\right)_{S_{22}}-\sum_{j=1}^{5}\left(C_{2 j}\right)_{S_{22}} \\
\sum_{i=1}^{2}\left(I_{3 i}\right)_{S_{31}}-\sum_{j=1}^{2}\left(C_{3 j}\right)_{S_{31}}\end{array}$ & $\begin{array}{l}\sum_{i=1}^{3}\left(I_{1 i}\right)_{S_{11}}-\sum_{j=1}^{5}\left(C_{1 j}\right)_{S_{11}} \\
\sum_{i=1}^{3}\left(I_{2 i}\right)_{S_{23}}-\sum_{j=1}^{5}\left(C_{2 j}\right)_{S_{23}} \\
\sum_{i=1}^{2}\left(I_{3 i}\right)_{S_{31}}-\sum_{j=1}^{2}\left(C_{3 j}\right)_{S_{31}}\end{array}$ \\
\hline $\begin{array}{l}\text { Government } \\
\text { strategy }=S_{12}\end{array}$ & $\begin{array}{l}\sum_{i=1}^{3}\left(I_{1 i}\right)_{S_{12}}-\sum_{j=1}^{5}\left(C_{1 j}\right)_{S_{12}} \\
\sum_{i=1}^{3}\left(I_{2 i}\right)_{S_{21}}-\sum_{j=1}^{5}\left(C_{2 j}\right)_{S_{21}} \\
\sum_{i=1}^{2}\left(I_{3 i}\right)_{S_{31}}-\sum_{j=1}^{2}\left(C_{3 j}\right)_{S_{31}}\end{array}$ & $\begin{array}{l}\sum_{i=1}^{3}\left(I_{1 i}\right)_{S_{12}}-\sum_{j=1}^{5}\left(C_{1 j}\right)_{S_{12}} \\
\sum_{i=1}^{3}\left(I_{2 i}\right)_{S_{22}}-\sum_{j=1}^{5}\left(C_{2 j}\right)_{S_{22}} \\
\sum_{i=1}^{2}\left(I_{3 i}\right)_{S_{31}}-\sum_{j=1}^{2}\left(C_{3 j}\right)_{S_{31}}\end{array}$ & $\begin{array}{l}\sum_{i=1}^{3}\left(I_{1 i}\right)_{S_{12}}-\sum_{j=1}^{5}\left(C_{1 j}\right)_{S_{12}} \\
\sum_{i=1}^{3}\left(I_{2 i}\right)_{S_{23}}-\sum_{j=1}^{5}\left(C_{2 j}\right)_{S_{23}} \\
\sum_{i=1}^{2}\left(I_{3 i}\right)_{S_{31}}-\sum_{j=1}^{2}\left(C_{3 j}\right)_{S_{31}}\end{array}$ \\
\hline $\begin{array}{l}\text { Government } \\
\text { strategy }=S_{13}\end{array}$ & $\begin{array}{l}\sum_{i=1}^{3}\left(I_{1 i}\right)_{S_{13}}-\sum_{j=1}^{5}\left(C_{1 j}\right)_{S_{13}} \\
\sum_{i=1}^{3}\left(I_{2 i}\right)_{S_{21}}-\sum_{j=1}^{5}\left(C_{2 j}\right)_{S_{21}} \\
\sum_{i=1}^{2}\left(I_{3 i}\right)_{S_{31}}-\sum_{j=1}^{2}\left(C_{3 j}\right)_{S_{31}}\end{array}$ & $\begin{array}{l}\sum_{i=1}^{3}\left(I_{1 i}\right)_{S_{13}}-\sum_{j=1}^{5}\left(C_{1 j}\right)_{S_{13}} \\
\sum_{i=1}^{3}\left(I_{2 i}\right)_{S_{22}}-\sum_{j=1}^{5}\left(C_{2 j}\right)_{S_{22}} \\
\sum_{i=1}^{2}\left(I_{3 i}\right)_{S_{31}}-\sum_{j=1}^{2}\left(C_{3 j}\right)_{S_{31}}\end{array}$ & $\begin{array}{l}\sum_{i=1}^{3}\left(I_{1 i}\right)_{S_{13}}-\sum_{j=1}^{5}\left(C_{1 j}\right)_{S_{13}} \\
\sum_{i=1}^{3}\left(I_{2 i}\right)_{S_{23}}-\sum_{j=1}^{5}\left(C_{2 j}\right)_{S_{23}} \\
\sum_{i=1}^{2}\left(I_{3 i}\right)_{S_{31}}-\sum_{j=1}^{2}\left(C_{3 j}\right)_{S_{31}}\end{array}$ \\
\hline
\end{tabular}

Table 5. Matrix model for Customer's strategy $=S_{32}$

\begin{tabular}{|c|c|c|c|}
\hline & $\begin{array}{l}\text { Manufacturer } \\
\text { strategy }=S_{21}\end{array}$ & $\begin{array}{l}\text { Manufacturer } \\
\text { strategy }=\boldsymbol{S}_{22}\end{array}$ & $\begin{array}{l}\text { Manufacturer } \\
\text { strategy }=\boldsymbol{S}_{23}\end{array}$ \\
\hline $\begin{array}{l}\text { Government } \\
\text { strategy }=S_{11}\end{array}$ & $\begin{array}{l}\sum_{i=1}^{3}\left(I_{1 i}\right)_{S_{11}}-\sum_{j=1}^{5}\left(C_{1 j}\right)_{S_{11}} \\
\sum_{i=1}^{3}\left(I_{2 i}\right)_{S_{21}}-\sum_{j=1}^{5}\left(C_{2 j}\right)_{S_{21}} \\
\sum_{i=1}^{2}\left(I_{3 i}\right)_{S_{32}}-\sum_{j=1}^{2}\left(C_{3 j}\right)_{S_{32}}\end{array}$ & $\begin{array}{l}\sum_{i=1}^{3}\left(I_{1 i}\right)_{S_{11}}-\sum_{j=1}^{5}\left(C_{1 j}\right)_{S_{11}} \\
\sum_{i=1}^{3}\left(I_{2 i}\right)_{S_{22}}-\sum_{j=1}^{5}\left(C_{2 j}\right)_{S_{22}} \\
\sum_{i=1}^{2}\left(I_{3 i}\right)_{S_{32}}-\sum_{j=1}^{2}\left(C_{3 j}\right)_{S_{32}}\end{array}$ & $\begin{array}{l}\sum_{i=1}^{3}\left(I_{1 i}\right)_{S_{11}}-\sum_{j=1}^{5}\left(C_{1 j}\right)_{S_{11}} \\
\sum_{i=1}^{3}\left(I_{2 i}\right)_{S_{23}}-\sum_{j=1}^{5}\left(C_{2 j}\right)_{S_{23}} \\
\sum_{i=1}^{2}\left(I_{3 i}\right)_{S_{32}}-\sum_{j=1}^{2}\left(C_{3 j}\right)_{S_{32}}\end{array}$ \\
\hline $\begin{array}{l}\text { Government } \\
\text { strategy }=S_{12}\end{array}$ & $\begin{array}{l}\sum_{i=1}^{3}\left(I_{1 i}\right)_{S_{12}}-\sum_{j=1}^{5}\left(C_{1 j}\right)_{S_{12}} \\
\sum_{i=1}^{3}\left(I_{2 i}\right)_{S_{21}}-\sum_{j=1}^{5}\left(C_{2 j}\right)_{S_{21}} \\
\sum_{i=1}^{2}\left(I_{3 i}\right)_{S_{32}}-\sum_{j=1}^{2}\left(C_{3 j}\right)_{S_{32}}\end{array}$ & $\begin{array}{l}\sum_{i=1}^{3}\left(I_{1 i}\right)_{S_{12}}-\sum_{j=1}^{5}\left(C_{1 j}\right)_{S_{12}} \\
\sum_{i=1}^{3}\left(I_{2 i}\right)_{S_{22}}-\sum_{j=1}^{5}\left(C_{2 j}\right)_{S_{22}} \\
\sum_{i=1}^{2}\left(I_{3 i}\right)_{S_{32}}-\sum_{j=1}^{2}\left(C_{3 j}\right)_{S_{32}}\end{array}$ & $\begin{array}{l}\sum_{i=1}^{3}\left(I_{1 i}\right)_{S_{12}}-\sum_{j=1}^{5}\left(C_{1 j}\right)_{S_{12}} \\
\sum_{i=1}^{3}\left(I_{2 i}\right)_{S_{23}}-\sum_{j=1}^{5}\left(C_{2 j}\right)_{S_{23}} \\
\sum_{i=1}^{2}\left(I_{3 i}\right)_{S_{32}}-\sum_{j=1}^{2}\left(C_{3 j}\right)_{S_{32}}\end{array}$ \\
\hline $\begin{array}{l}\text { Government } \\
\text { strategy }=S_{13}\end{array}$ & $\begin{array}{l}\sum_{i=1}^{3}\left(I_{1 i}\right)_{S_{13}}-\sum_{j=1}^{5}\left(C_{1 j}\right)_{S_{13}} \\
\sum_{i=1}^{3}\left(I_{2 i}\right)_{S_{21}}-\sum_{j=1}^{5}\left(C_{2 j}\right)_{S_{21}} \\
\sum_{i=1}^{2}\left(I_{3 i}\right)_{S_{32}}-\sum_{j=1}^{2}\left(C_{3 j}\right)_{S_{32}}\end{array}$ & $\begin{array}{l}\sum_{i=1}^{3}\left(I_{1 i}\right)_{S_{13}}-\sum_{j=1}^{5}\left(C_{1 j}\right)_{S_{13}} \\
\sum_{i=1}^{3}\left(I_{2 i}\right)_{S_{22}}-\sum_{j=1}^{5}\left(C_{2 j}\right)_{S_{22}} \\
\sum_{i=1}^{2}\left(I_{3 i}\right)_{S_{32}}-\sum_{j=1}^{2}\left(C_{3 j}\right)_{S_{32}}\end{array}$ & $\begin{array}{l}\sum_{i=1}^{3}\left(I_{1 i}\right)_{S_{13}}-\sum_{j=1}^{5}\left(C_{1 j}\right)_{S_{13}} \\
\sum_{i=1}^{3}\left(I_{2 i}\right)_{S_{23}}-\sum_{j=1}^{5}\left(C_{2 j}\right)_{S_{23}} \\
\sum_{i=1}^{2}\left(I_{3 i}\right)_{S_{32}}-\sum_{j=1}^{2}\left(C_{3 j}\right)_{S_{32}}\end{array}$ \\
\hline
\end{tabular}

Table 6. Matrix model for Customer's strategy $=\mathrm{S}_{33}$

\begin{tabular}{|c|c|c|c|}
\hline & $\begin{array}{l}\text { Manufacturer } \\
\text { strategy }=S_{21}\end{array}$ & $\begin{array}{l}\text { Manufacturer } \\
\text { strategy }=\boldsymbol{S}_{22}\end{array}$ & $\begin{array}{l}\text { Manufacturer } \\
\text { strategy }=\boldsymbol{S}_{23}\end{array}$ \\
\hline $\begin{array}{l}\text { Government } \\
\text { strategy }=S_{11}\end{array}$ & $\begin{array}{l}\sum_{i=1}^{3}\left(I_{1 i}\right)_{S_{11}}-\sum_{j=1}^{5}\left(C_{1 j}\right)_{S_{11}} \\
\sum_{i=1}^{3}\left(I_{2 i}\right)_{S_{21}}-\sum_{j=1}^{5}\left(C_{2 j}\right)_{S_{21}} \\
\sum_{i=1}^{2}\left(I_{3 i}\right)_{S_{33}}-\sum_{j=1}^{2}\left(C_{3 j}\right)_{S_{33}}\end{array}$ & $\begin{array}{l}\sum_{i=1}^{3}\left(I_{1 i}\right)_{S_{11}}-\sum_{j=1}^{5}\left(C_{1 j}\right)_{S_{11}} \\
\sum_{i=1}^{3}\left(I_{2 i}\right)_{S_{22}}-\sum_{j=1}^{5}\left(C_{2 j}\right)_{S_{22}} \\
\sum_{i=1}^{2}\left(I_{3 i}\right)_{S_{33}}-\sum_{j=1}^{2}\left(C_{3 j}\right)_{S_{33}}\end{array}$ & $\begin{array}{l}\sum_{i=1}^{3}\left(I_{1 i}\right)_{S_{11}}-\sum_{j=1}^{5}\left(C_{1 j}\right)_{S_{11}} \\
\sum_{i=1}^{3}\left(I_{2 i}\right)_{S_{23}}-\sum_{j=1}^{5}\left(C_{2 j}\right)_{S_{23}} \\
\sum_{i=1}^{2}\left(I_{3 i}\right)_{S_{33}}-\sum_{j=1}^{2}\left(C_{3 j}\right)_{S_{33}}\end{array}$ \\
\hline $\begin{array}{l}\text { Government } \\
\text { strategy }=S_{12}\end{array}$ & $\begin{array}{l}\sum_{i=1}^{3}\left(I_{1 i}\right)_{S_{12}}-\sum_{j=1}^{5}\left(C_{1 j}\right)_{S_{12}} \\
\sum_{i=1}^{3}\left(I_{2 i}\right)_{S_{21}}-\sum_{j=1}^{5}\left(C_{2 j}\right)_{S_{21}} \\
\sum_{i=1}^{2}\left(I_{3 i}\right)_{S_{33}}-\sum_{j=1}^{2}\left(C_{3 j}\right)_{S_{33}}\end{array}$ & $\begin{array}{l}\sum_{i=1}^{3}\left(I_{1 i}\right)_{S_{12}}-\sum_{j=1}^{5}\left(C_{1 j}\right)_{S_{12}} \\
\sum_{i=1}^{3}\left(I_{2 i}\right)_{S_{22}}-\sum_{j=1}^{5}\left(C_{2 j}\right)_{S_{22}} \\
\sum_{i=1}^{2}\left(I_{3 i}\right)_{S_{33}}-\sum_{j=1}^{2}\left(C_{3 j}\right)_{S_{33}}\end{array}$ & $\begin{array}{l}\sum_{i=1}^{3}\left(I_{1 i}\right)_{S_{12}}-\sum_{j=1}^{5}\left(C_{1 j}\right)_{S_{12}} \\
\sum_{i=1}^{3}\left(I_{2 i}\right)_{S_{23}}-\sum_{j=1}^{5}\left(C_{2 j}\right)_{S_{23}} \\
\sum_{i=1}^{2}\left(I_{3 i}\right)_{S_{33}}-\sum_{j=1}^{2}\left(C_{3 j}\right)_{S_{33}}\end{array}$ \\
\hline $\begin{array}{l}\text { Government } \\
\text { strategy }=S_{13}\end{array}$ & $\begin{array}{l}\sum_{i=1}^{3}\left(I_{1 i}\right)_{S_{13}}-\sum_{j=1}^{5}\left(C_{1 j}\right)_{S_{13}} \\
\sum_{i=1}^{3}\left(I_{2 i}\right)_{S_{21}}-\sum_{j=1}^{5}\left(C_{2 j}\right)_{S_{21}} \\
\sum_{i=1}^{2}\left(I_{3 i}\right)_{S_{33}}-\sum_{j=1}^{2}\left(C_{3 j}\right)_{S_{33}}\end{array}$ & $\begin{array}{l}\sum_{i=1}^{3}\left(I_{1 i}\right)_{S_{13}}-\sum_{j=1}^{5}\left(C_{1 j}\right)_{S_{13}} \\
\sum_{i=1}^{3}\left(I_{2 i}\right)_{S_{22}}-\sum_{j=1}^{5}\left(C_{2 j}\right)_{S_{22}} \\
\sum_{i=1}^{2}\left(I_{3 i}\right)_{S_{33}}-\sum_{j=1}^{2}\left(C_{3 j}\right)_{S_{33}}\end{array}$ & $\begin{array}{l}\sum_{i=1}^{3}\left(I_{1 i}\right)_{S_{13}}-\sum_{j=1}^{5}\left(C_{1 j}\right)_{S_{13}} \\
\sum_{i=1}^{3}\left(I_{2 i}\right)_{S_{23}}-\sum_{j=1}^{5}\left(C_{2 j}\right)_{S_{23}} \\
\sum_{i=1}^{2}\left(I_{3 i}\right)_{S_{33}}-\sum_{j=1}^{2}\left(C_{3 j}\right)_{S_{33}}\end{array}$ \\
\hline
\end{tabular}




\section{Modelling with Fuzzy Sets and Sensitive Analysis}

As described earlier, and due to nature of the problem, the decision making parameters and major uncertain variables can be interpolated to fuzzy sets. Then, we can claim that, the entire model and its achieved results are, somehow, more efficient and practical in order to achieve optimal results. The consideration of fuzzy set can increase of confidence level for players to make decision on changing the status. Among of the all existing variables, the ones of making decision by customers are said to be of higher membership degree. In reality, if the variables making decision by customer are major parameters in calculating pay-off function and can be regarded as certain states with membership degree of value equal to 1 , then the exact optimal results will not be achieved.

In fact, any other value not necessarily zero -customers is not interested enoughwhich can be considered by the other subsidiaries of the game, where, their decisions will not be affected, even if the final achieved pay-off value is higher than what it was before. On the other hand, other variables, for instance, benefits resulting from sustainable development may not reflect the positive effect of the customers pay-off function. Accordingly, we can model these notices as:

$$
\begin{aligned}
& \text { if } I_{31}+I_{32}-\partial C_{31}<B_{1} \text { then } S_{31} \\
& \text { if } I_{31}+I_{32}-\partial C_{31}<B_{1} \text { then } S_{32} \\
& \text { if } I_{31}+I_{32}-\partial C_{31}<B_{1} \text { then } S_{33}
\end{aligned}
$$

Where $B_{1}$ and $B_{2}$ are attraction levels of sum of incomes resulting from facilities and long-term interests of sustainable development for decision-making and $B_{2}>B_{1}$. For the matter of fact, we expect that all players (especially customers), have no accurate and detailed view to draw decision depending on the result of Pay-off function. Then we can assume that customers will draw their pay-off function qualitatively, rather than numerically.

Fuzzy set theory can be very applicable to this kind of analysis. Now if the customer pay-off variables are considered as the fuzzy sets, then customer behaviour will be linguistically predictable and thus reflects change in variable value. This principle motivates the other players, government and manufacturer to take the optimal value for their related variables in order to positively modify customer inquiries or at least keep it steady.

To achieve more practical game model, and to more towards the optimal solution, a model based on fuzzy set is constructed as follows, which is adapted from [22].

Step 1: Specify the variables to be represented as fuzzy sets:

Fuzzy sets:

$$
C_{12}, C_{23}, \partial C_{31}, I_{32}, P_{3}
$$


Step 2: Specify fuzzy implications:

$$
C_{12}, C_{23}, \partial C_{31}, I_{32} \rightarrow \partial P_{3}
$$

Step 3: Assign linguistic values to fuzzy sets.

Linguistic values set of each variable can be defined as:

$$
X=\left\{x_{1}, x_{2}, \ldots, x_{n}\right\}
$$

In this research, these variables can be defined by the following fuzzy sets:

$$
\begin{aligned}
& C_{12}=\{\text { Unfavorable }(U F), \text { Favorite }(F)\} \\
& C_{23}=\{\text { Unfavorable }(U F), \text { Favorite }(F)\} \\
& \partial C_{31}=\{\operatorname{Low}(L), \operatorname{High}(H)\} \\
& I_{32}=\{\operatorname{Low}(L), \operatorname{High}(H)\} \\
& P_{3}=\{\operatorname{Negative}(N), \operatorname{Zero}(Z), \text { Positive }(P)\}
\end{aligned}
$$

For the above described sets: negative linguistic value in pay-off function represents no interest to change in demand, zero represents passive response in making decision and, positive represents willing to change demand.

Step 4: Calculation of membership degree for every linguistic value:

$$
\begin{aligned}
& \mu_{C_{12}(U F)}=\mu_{1}(x) \\
& \mu_{C_{12}(F)}=\mu_{2}(x) \\
& \mu_{C_{23}(U F)}=\mu_{3}(x) \\
& \mu_{C_{23}(F)}=\mu_{4}(x) \\
& \mu_{\partial C_{31}(L)}=\mu_{5}(x) \\
& \mu_{\partial C_{23}(H)}=\mu_{6}(x) \\
& \mu_{I_{32}(L)}=\mu_{7}(x) \\
& \mu_{I_{32}(H)}=\mu_{8}(x) \\
& \mu_{P_{3}(N)}=\mu_{9}(x) \\
& \mu_{P_{3}(Z)}=\mu_{10}(x) \\
& \mu_{P_{3}(P)}=\mu_{11}(x)
\end{aligned}
$$

Step 5: Implementing the fuzzy inference: Among the available fuzzy inference systems, Mamadani inference [22] is elected in this problem, where: the inputs: $C_{12}, C_{23}, \partial C_{31}$, and $I_{32}$, and the output is $P_{3}$, then Rule ${ }_{i}$ can be defined as:

$$
\begin{gathered}
\text { if } C_{12 i}, C_{23 i}, \partial C_{31 i}, I_{32 i} \text { then } P_{3 i} \\
a_{i}=\min \left(\mu_{i}\left(C_{12}\right), \mu_{i}\left(C_{23}\right), \mu_{i}\left(\partial C_{31}\right), \mu_{i} I_{32}\right) \\
\mu_{i}=\min \left(a_{i}, \mu_{P_{3 i}}\right)
\end{gathered}
$$


The overall system output can be calculated using the union operator as:

$$
\mu=\cup \mu_{i}
$$

Where $\mu$ is member function of fuzzy sets, $a_{i}$ is the $i^{\text {th }}$ alpha cut of fuzzy set. Where, finally the Defuzzification process should take place. In our case the fuzzy result will be used in the next step.

Step 6: Specifying the logical relationships: group of relationships between the final result and the predicted customers' decisions. This relationship can be described as follows:

$$
\begin{aligned}
& \text { If } 0 \leq \theta \leq l \rightarrow S_{31} \\
& \text { f } l<\theta \leq m \rightarrow S_{32} \\
& \text { If } m<\theta \leq h \rightarrow S_{33} \\
& 0<l<m<h
\end{aligned}
$$

Where $\theta$ is the fuzzy result of the problem, $l$ is the minimal qualitative pay-off value, possibly customers that would show of decrease in demand. $m$ is the mean qualitative pay-off value, customers that show no interest in changing the demand. And $h$ is the maximal qualitative pay-off value for customers that show satisfaction and possibly of increase in demand. This pattern analysis outperforms the sensitivity analysis of customers pay-off function which is described in the next part. result:

Step 7: Applying sensitivity analysis to customers' pay-off, and choosing optimal

To analyse pay-off function, we assume that $a, b, c$ and, $d$ are four input parameters with different values. In this case there will be $a \times b \times c \times d$. In a collaborative game and after achieving results of sensitivity analysis for customers' behaviour, the other game players undertake the optimal value of governmental incentive facilities parameters for customers, the optimal value of incentive facilities of manufacturer, and the optimal value of increase in products price due to change technology levels.

\section{Simulation of the Proposed Fuzzy Model and Optimal Solution}

To evaluate the proposed model, a Matlab program was constructed to compute the defuzzified output of this fuzzy model, the results as extracted to Microsoft excel sheet as shown in Fig. 1. Which contains the major parts of the system, first the input vector, Rule Base for the inference system which consists of set of 16 if-then rules as explained in Step 5, the membership value for each rule with respect to the input vector, the aggregated membership function value for the output, and finally computing the defuzzified result, which will be used by experts to make the decision. According to the 
example in Fig. 1, if $I_{32}=0.5, \partial C_{31}=1.5, C_{23}=3$, and $C_{12}=2$, then, the accumulated final result is $8 \%$, which indicates the customers conceive to modify the corresponding pay-off. Nevertheless, the achieved $8 \%$ is not quantitative rather than qualitative measure that indicates enough information about the customers' ability for making-decision about certain product.

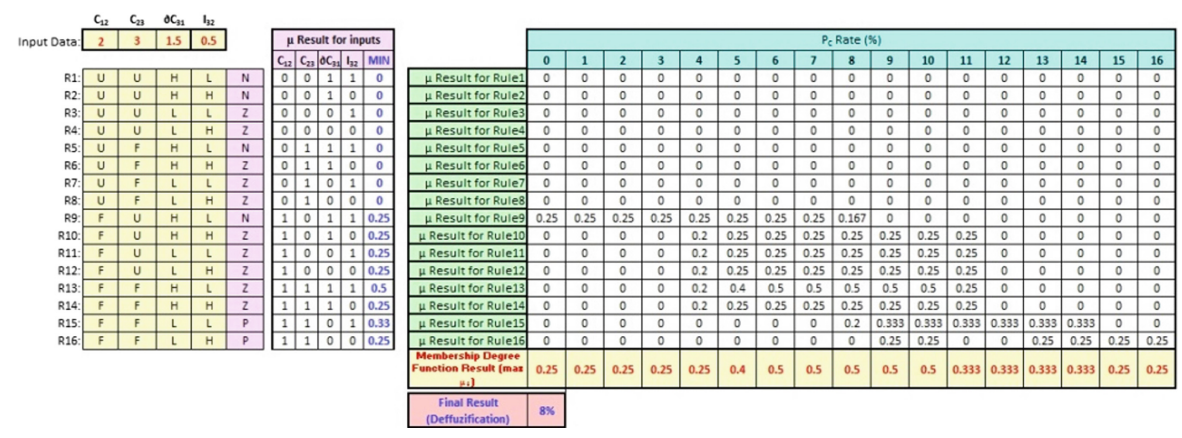

Fig. 1. Program sample results

The optimal result of decision-making for all the players can be computed as:

$$
\max _{s_{i} \in S_{i}} u_{i}\left(S_{i}, S_{-i}\right)
$$

Games are seeking of the optimal pay-off function for player ( $i$ ) in front of combination of strategies related to this particular player strategy $\left(S_{i}\right)$ with other strategies of all players except player $\left(S_{-i}\right)$.

Nash Equilibrium presented in [23, 25] is said to provide optimal result for those kind of problems, where Nash stated that "an n-tuples such that each player's mixed strategy maximizes his pay-off if the strategies of the others are held fixed. Thus each player's strategy is optimal against those of the others" [25]. In our case, there is a combination of strategies among all combinations in game model at least that players are not interested to change that in a logical condition. Since the game is a dynamic with the complete information, if the Nash equilibrium is iteratively earned more than once, then the optimal result would be achieved via complete equilibrium or backward Nash equilibrium [24]. This optimal result can be achieved by the analysis of the resultant Nash equilibrium. One of the techniques, which can be used to obtain this result, is by converting the original game model to a secondary game model. Finally is gaining final result by all results of the secondary game.

\section{Numerical Analysis}

Taking numerical example can ease the description of the process. Our example presumes that Alain Cement manufacturer in Alain city is planning to update the production technology in order to decrease the impact on the environment, and drop the 
flow gas of factory to the new standardized level. After 6 months of study by the research and development department of this manufacturer, the total principle to invest, possible benefits and income, machinery update cost, labor training cost, and other required variables are listed in the following table (Table 7):

Table 7. Variables and data assumption

\begin{tabular}{l|l|l}
\hline$n=10$ (years) & $i=10 \%$ & $\alpha=0.03$ \\
\hline$\beta_{1}=0.02$ & $\beta_{2}=0.03$ & $\rho_{1}=-0.2$ \\
\hline$\rho_{2}=0.1$ & $I_{12}=0.45 C_{12}$ & $I_{13(A)}=2 m \$$ \\
\hline$I_{13(B)}=5 m \$$ & $C_{11}=1.25 m \$$ & $\gamma C_{12}=0.40 C_{21}$ \\
\hline$(1-\gamma) C_{12}=[0,2.5] m \$$ & & $C_{13(A)}=5 m \$$ \\
\hline$C_{13(B)}=2 m \$$ & $C_{14(A)}=3 m \$$ & $C_{14(B)}=1 m \$$ \\
\hline$C_{15(A)}=1 m \$$ & $C_{15(B)}=2 m \$$ & $I_{21}: 65 m \$$ \\
\hline$I_{23(A)}=1 m \$$ & $I_{23(B)}=3 m \$$ & $C_{21(A)}=40 m \$$ \\
\hline$C_{21(B)}=60 m \$$ & $C_{22(A)}=50 m \$$ & $C_{22(B)}=48 m \$$ \\
\hline$C_{22(C)}=47 m \$$ & $C_{23(A)}=[0,5] m \$$ & $C_{24(A)}=3 m \$$ \\
\hline$C_{24(B)}=1 m \$$ & $C_{24(C)}=0.65 m \$$ & $\partial C_{22}=0.5 \rho * C_{22}$ \\
\hline$I_{32(A)}=0.5 m \$$ & $I_{32(B)}=1 m \$$ & $C_{32(A)}=3 m \$$ \\
\hline$C_{32(B)}=1 m \$$ & $\varepsilon=0.01 m \$$ & \\
\hline
\end{tabular}

Note, the definition of the variables in the above table follows the same predescribed definition. And, the following assumptions can be made to solve this problem:

The problem assumes two stages, first is classical model, and second is the fuzzy sets based model. In the classical model, the two players the government and the manufacturer enrolled in technology change, while customer tolerable level uses $50 \%$ of subsidiary total. Also, manufacturer assumes the highest value of production price.

Status of reduction of customer demand, product purchasing cost variable for the loyalty customers is calculated based on the new prices, on the other hand, for the lost customers is calculated according to product purchasing cost. While the Sub costs of the manufacturer and government is changing according to the consumers' demands.

Likewise, consumer's income from this update will change also according to the demand.

Assume that symbol A represents the intolerable level in sustainable development of the environment. Symbol B represents the tolerable level of this change, and symbol $\mathrm{C}$ represents acceptable level. The total update cost is converted to yearly constant cost as shown in the following formula:

$$
A=P(A / P, i \%, n) \rightarrow A=P(A / P, 10 \%, 10)
$$

The second model is built based on fuzzy sets according to the pre-described relations (5-9), and then the final fuzzy membership degrees and their corresponding triangular membership functions are illustrated in Fig. 2. Using the Matlab program some results of (10) are shown in Fig. 3 and in Table 8. 

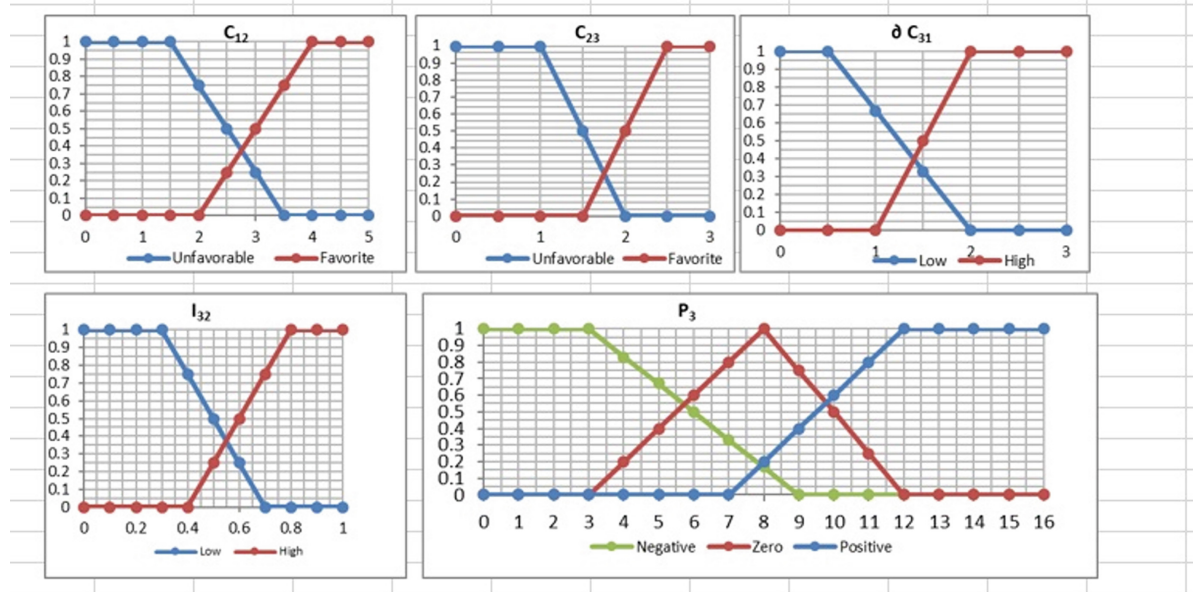

Fig. 2. The results membership functions
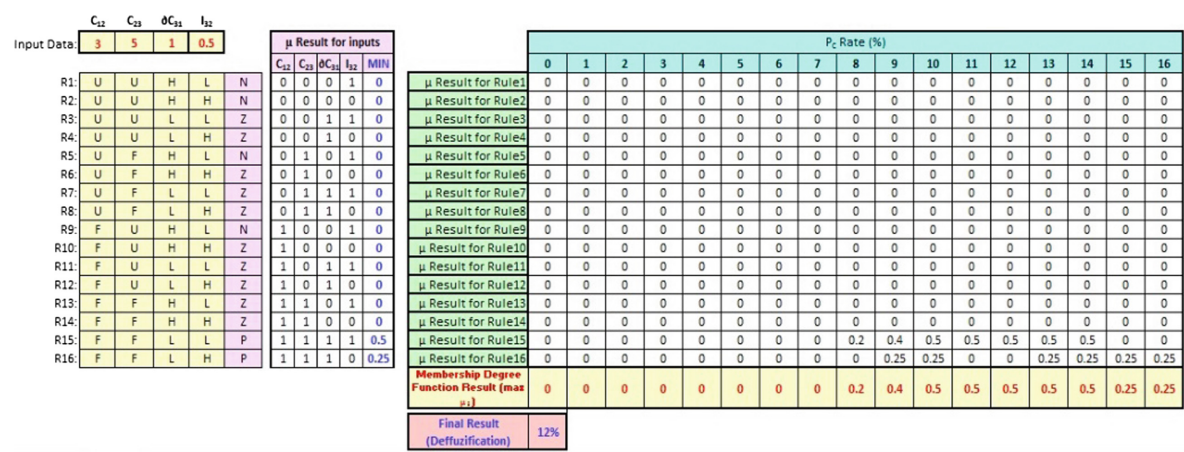

Fig. 3. Results of the fuzzy inference for the problem

Looking back at model (12), logical rules between fuzzy inference results and consumers decision-making are listed here:

$$
\begin{gathered}
\text { if } 0 \leq \theta \leq 5 \% \rightarrow S_{31} \\
\text { if } 5 \%<\theta<10 \% \rightarrow S_{32} \\
\text { if } 10 \leq \theta \rightarrow S_{33}
\end{gathered}
$$

Using the sensitivity analysis of consumers pay-offs for another data sets other than the ones used in Fig. 2, after implementing the aforementioned logical relations, then, optimal parameters of this change may look like: 


$$
C_{12}=0, C_{23}=0, \partial C_{31}=1 \%, I_{32}=0.5, \partial P_{3}=8 \%
$$

This optimal solution considers that, governments are not going utilize incentive costs of facilities to update the technology in the acceptable and tolerable levels.

But if the governments are willing to implement the incentive costs, then the optimal solution for tolerable level, and acceptable level respectively can be re-modeled as follows:

$$
\begin{aligned}
& C_{12}=1.5, C_{23}=0, \partial C_{31}=1 \%, I_{32}=0.5, \partial P_{3}=8 \% \\
& C_{12}=3, C_{23}=3, \partial C_{31}=1.5 \%, I_{32}=1, \partial P_{3}=10 \%
\end{aligned}
$$

Where, $\partial P_{3}$ shows increase in Customers' pay-off function than the previous level in that. Some of the results of consumers pay-offs are shown in Table 8:

Table 8. Consumers pay-offs

\begin{tabular}{l|l|l|l|l}
\hline $\boldsymbol{C}_{12}$ & $\boldsymbol{C}_{23}$ & $\partial \boldsymbol{C}_{31}$ & $\boldsymbol{I}_{32}$ & $\boldsymbol{P}_{3}$ \\
\hline 0.0 & 0.0 & 2.0 & 0.5 & $4.0 \%$ \\
\hline 1.0 & 4.0 & 1.5 & 0.5 & $5.0 \%$ \\
\hline 3.0 & 2.5 & 2.5 & 0.5 & $5.0 \%$ \\
\hline 3.0 & 3.0 & 2.5 & 0.5 & $6.0 \%$ \\
\hline 2.0 & 3.0 & 3.0 & 0.5 & $6.0 \%$ \\
\hline 3.0 & 2.5 & 1.5 & 0.5 & $7.0 \%$ \\
\hline 2.0 & 2.5 & 1.5 & 0.5 & $7.0 \%$ \\
\hline 0.0 & 1.0 & 0.0 & 0.5 & $8.0 \%$ \\
\hline 0.0 & 0.0 & 1.0 & 0.5 & $8.0 \%$ \\
\hline 1.5 & 0.0 & 1.0 & 0.5 & $8.0 \%$ \\
\hline 2.5 & 2.5 & 1.0 & 0.5 & $9.0 \%$ \\
\hline 3.0 & 3.0 & 1.5 & 1.0 & $10.0 \%$ \\
\hline 3.0 & 4.0 & 1.5 & 0.5 & $10.0 \%$ \\
\hline 3.0 & 3.0 & 1.0 & 0.5 & $11.0 \%$ \\
\hline 3.0 & 3.0 & 0.0 & 0.5 & $11.0 \%$ \\
\hline 3.0 & 5.0 & 1.0 & 0.5 & $12.0 \%$ \\
\hline
\end{tabular}

Then, the matrix of the game can be shown in Table 9.

Table 9. Fuzzy sets based model- Consumer Strategy $=\mathrm{S}_{31}$

\begin{tabular}{l|l|l|l}
\hline & $\boldsymbol{S}_{21}$ & $\boldsymbol{S}_{22}$ & $\boldsymbol{S}_{23}$ \\
\hline $\boldsymbol{S}_{11}$ & $-8,4,-68$ & $-3,2.82,-66$ & $2,2.81,-64.7$ \\
\hline $\boldsymbol{S}_{12}$ & $-7.7,2.4,-68$ & $-3,2.82,-66$ & $2,2.81,-64.7$ \\
\hline $\boldsymbol{S}_{13}$ & $-7.7,2.4,-68$ & $-2.7,6.1,-65$ & $0.1,5.55,-59.4$ \\
\hline
\end{tabular}


After implementing the Nash Equilibrium and its Backward version based on the (2, 3, 4 and 12), and Tables 4, 5 and 6. Then Tables 10 and 11 show the optimal answers of each parameter.

Table 10. Fuzzy sets based model- Consumer Strategy $=\mathrm{S}_{32}$

\begin{tabular}{l|l|l|l}
\hline & $\boldsymbol{S}_{21}$ & $\boldsymbol{S}_{22}$ & $\boldsymbol{S}_{23}$ \\
\hline $\boldsymbol{S}_{11}$ & $-8,12,-68$ & $-3,11.1,-66.2$ & $2,10.6,-64.7$ \\
\hline $\boldsymbol{S}_{12}$ & $-7.3,10,-68$ & $-3,11.1,-66.2$ & $2,10.6,-64.7$ \\
\hline $\boldsymbol{S}_{13}$ & $-7.3,10,-68$ & $-3,14.4,-66$ & $-0.5,14,-59$ \\
\hline
\end{tabular}

Table 11. Fuzzy sets based model- Consumer Strategy $=\mathrm{S}_{33}$

\begin{tabular}{l|l|l|l}
\hline & $\boldsymbol{S}_{21}$ & $\boldsymbol{S}_{22}$ & $\boldsymbol{S}_{23}$ \\
\hline $\boldsymbol{S}_{11}$ & $-8,16,-68.01$ & $-3,15.3,-66.2$ & $2,15.4,-64.7$ \\
\hline $\boldsymbol{S}_{12}$ & $-7.1,13.8,-68.01$ & $-3,15.3,-66.2$ & $2,15.4,-64.7$ \\
\hline $\boldsymbol{S}_{13}$ & $-7.1,13.8,-68.1$ & $-3,18.6,-65$ & $-0.8,15.7,-57.1$ \\
\hline
\end{tabular}

Considering to above tables, the optimal answers of fuzzy set based is formulated as:

$$
\begin{aligned}
& N(G)_{1}=\left(S_{13}, S_{22}, S_{31}\right)=(-2.7,6.1,-65) \\
& N(G)_{2}=\left(S_{13}, S_{22}, S_{33}\right)=(-3,18.6,-65)
\end{aligned}
$$

$S P E=\left(S_{13}, S_{22}, S_{33}\right)=(-3,18.6,-65) \rightarrow$ optimal result based on fuzzy sets model

Carrying out our analysis separately, (for classical model), the optimal results can be:

$$
\begin{gathered}
N(G)_{1}=\left(S_{12}, S_{21}, S_{31}\right)=(-7.7,2.4,-68) \\
N(G)_{2}=\left(S_{12}, S_{21}, S_{32}\right)=(-7.3,10,-68) \\
N(G)_{3}=\left(S_{13}, S_{22}, S_{32}\right)=(-3,11.9,-62.8)
\end{gathered}
$$

$\operatorname{SPE}(G)=\left(S_{13}, S_{22}, S_{32}\right)=(-3,11.9,-62.8) \rightarrow$ optimal result based on classical model

Considering both results the classical version and the fuzzy set based one, it is clear that in fuzzy set based version, the results of Nash equilibrium and its Backward version are different than the classical version. And, it can propose different strategies. In the optimal solution of the fuzzy set based version model, government adapts strategies of sub system and monitory process while, manufacturer can update its technology from intolerable to the tolerable level. Consumers demand will show 
positive attitude to this update status. Considering the classical based version, the optimal solution indicated that consumers choose passive strategy while both pay-offs of manufacturer and consumers are reduced.

\section{Conclusion}

The strategies among three players of a green supply chain have been solved and modelled by using the game theory. In order to achieve practical model, initially, the proposed model merged the consumers strategies and main variables of pay-offs for three players by using fuzzy logic relations. Later, using analytical models and relations sensitively analyse the consumers pay-offs by modifying the fuzzy variables. Moreover, the used problem solving method proposes Nash equilibrium and its backward version. Finally, a numerical analysis was done and problem modelling and solving was accomplished using fuzzy set based version and classical version, and their results were compared with each other. The achieved results showed that the fuzzy set based version optimizes pay-offs for the three players more than the classical version, which results to change strategies of the players and thus motivates to move forward into a green strategy.

\section{References}

1. Blanchard, D.: Supply Chain Management Best Practices, 2nd edn. Wiley, Hoboken (2010)

2. Harrison, A., van Hoek, R.I.: Logistics Management and Strategy: Competing Through the Supply Chain. Pearson/Financial Times Prentice Hall, Upper Saddle River (2011)

3. Hines, T.: Supply Chain Strategies: Customer Driven and Customer Focused. Elsevier Butterworth-Heinemann, Oxford (2004)

4. Oliver, R.K., Webber, M.D.: Supply-chain management: logistics catches up with strategy. In: The Roots of Logistics: A Reader of Classical Contributions to the History and Conceptual Foundations of the Science of Logistics, pp. 183-194. Springer, Berlin (2012)

5. Sheu, J.-B., Chou, Y.-H., Hu, C.-C.: An integrated logistics operational model for greensupply chain management. Transp. Res. Part E Logist. Transp. Rev. 41(4), 287-313 (2005)

6. Basu, R.: Total Supply Chain Management. Routledge, Abingdon (2016)

7. Zhu, Q., Cote, R.P.: Integrating green supply chain management into an embryonic ecoindustrial development: a case study of the Guitang Group. J. Clean. Prod. 12(8-10), 10251035 (2004)

8. Zhu, Q., Sarkis, J., Lai, K.: Confirmation of a measurement model for green supply chain management practices implementation. Int. J. Prod. Econ. 111(2), 261-273 (2008)

9. Wang, H.-F., Gupta, S.M.: Green Supply Chain Management: Product Life Cycle Approach. McGraw Hill, New York (2011)

10. Wang, H.-F.: Web-Based Green Products Life Cycle Management Systems: Reverse Supply Chain Utilization. Information Science Reference, Hershey (2009)

11. Zhao, R., Deutz, P., Neighbour, G., McGuire, M.: Carbon emissions intensity ratio: an indicator for an improved carbon labelling scheme. Environ. Res. Lett. 7(1), 014014 (2012)

12. Cachon, G.P., Netessine, S.: Game Theory in Supply Chain Analysis, vol. 74. Springer, Boston, MA (2004) 
13. Esmaeili, M., Aryanezhad, M.-B., Zeephongsekul, P.: A game theory approach in sellerbuyer supply chain. Eur. J. Oper. Res. 195(2), 442-448 (2009)

14. Li, S.X., Huang, Z., Zhu, J., Chau, P.Y.K.: Cooperative advertising, game theory and manufacturer-retailer supply chains. Omega 30(5), 347-357 (2002)

15. Nagarajan, M., Sošić, G.: Game-theoretic analysis of cooperation among supply chain agents: review and extensions. Eur. J. Oper. Res. 187(3), 719-745 (2008)

16. Yue, J., Austin, J., Wang, M.-C., Huang, Z.: Coordination of cooperative advertising in a two-level supply chain when manufacturer offers discount. Eur. J. Oper. Res. 168(1), 65-85 (2006)

17. Zhu, Q., Dou, Y.: Evolutionary game model between governments and core enterprises in greening supply chains. Syst. Eng. - Theory Pract. 27(12), 85-89 (2007)

18. Chen, Y.J., Sheu, J.-B.: Environmental-regulation pricing strategies for green supply chain management. Transp. Res. Part E Logist. Transp. Rev. 45(5), 667-677 (2009)

19. Sheu, J.-B.: Bargaining framework for competitive green supply chains under governmental financial intervention. Transp. Res. Part E Logist. Transp. Rev. 47(5), 573-592 (2011)

20. Barari, S., Agarwal, G., (Chris) Zhang, W.J., Mahanty, B., Tiwari, M.K.: A decision framework for the analysis of green supply chain contracts: An evolutionary game approach. Expert Syst. Appl. 39(3), 2965-2976 (2012)

21. Nagurney, A., Yu, M.: Sustainable fashion supply chain management under oligopolistic competition and brand differentiation. Int. J. Prod. Econ. 135(2), 532-540 (2012)

22. Kahraman, C.: Fuzzy Applications in Industrial Engineering. Springer-Verlag, Berlin (2006)

23. Hart, S., Mas-Colell, A.: Stochastic uncoupled dynamics and Nash equilibrium. Games Econ. Behav. 57, 286-303 (2006)

24. Colell, A.M.: Bargaining Games. In: Cooperation: Game-Theoretic Approaches, pp. 69-90. Springer, Berlin, Heidelberg (1997)

25. Hart, S.: Nash Equilibrium and Dynamics (2008) 